\title{
LMB-2 Immunotoxin
}

National Cancer Institute

\section{Source}

National Cancer Institute. LMB-2 Immunotoxin. NCI Thesaurus. Code C2513.

A fusion protein consisting of the Fv portion of a monoclonal antibody attached to a 38kDa fragment of the Pseudomonas exotoxin A (with amino acids 365-380 deleted). LMB2 immunotoxin targets the interleukin 2 receptor (also known as IL-2R or CD25) which is expressed on activated normal T and B cells and macrophages and on the cells of various hematologic malignancies. The antibody attaches to the IL-2R on the cell membrane, facilitating the entry of the exotoxin. The exotoxin moiety induces caspasemediated apoptosis of tumor cells via a mechanism involving mitochondrial damage; it also catalyzes the transfer of ADP ribose from nicotinamide adenine dinucleotide (NAD) to elongation factor-2 in eukaryotic cells, thereby inactivating elong ation factor 2 and inhibiting protein synthesis. ( $\mathrm{NCl04)}$ 